\title{
Activity-Based Management for Electronic Commerce: A Structured Implementation Procedure
}

\author{
Narcyz Roztocki ${ }^{1}$ \\ ${ }^{1}$ State University of New York at New Paltz, School of Business, roztockn@newpaltz.edu \\ Received 15 February 2009; received in revised form 17 December 2009; accepted 30 January 2010
}

\begin{abstract}
This paper explores the application of Activity-Based Costing and Activity-Based Management in ecommerce. The proposed application may lead to better firm performance of many companies in offering their products and services over the Internet. A case study of a fictitious Business-to-Customer (B2C) company is used to illustrate the proposed structured implementation procedure and effects of an Activity-Based Costing analysis. The analysis is performed by using matrixes in order to trace overhead. The Activity-Based Costing analysis is then used to demonstrate operational and strategic Activity-Based Management in e-commerce.
\end{abstract}

Key words: Activity-Based Costing, Cost Control, Costing System, Customer Profitability, ECommerce, Activity-Based Management 


\section{Introduction}

During the period from the late 1990s until the spring of 2000, a then emerging technology, the Internet, created unprecedented over-optimism about investing in Internet start-ups [17]. In the following crash, starting in April 2000, many well-known Internet companies, such as boo.com, e-Toys, garden.com, pets.com, and streamline.com, have terminated their business operations and disappeared from the marketplace [16]. Although many investors have lost both their money and their faith in the "New Economy," the Internet is now a standard way to conduct business.

However, even today, e-commerce presents a substantial risk [7] and many Internet companies experience higher overall costs than comparable, traditional or click-and-brick companies [10]. One of many reasons for this cost disadvantage of Internet firms could be suspected in the absence of proper cost management systems in these firms. Activity-Based Costing (ABC) is a cost management system which has already proven successful in keeping costs under control for traditional companies and has been investigated for its possible implementation in Internet firms [12].

In the last three decades, $A B C$ was implemented mainly in large manufacturing and service companies as a replacement for volume-based costing systems [8], [9]. The main motivation for replacing traditional cost methods by $A B C$ was the frequent inappropriate allocation of costs that become detrimental to decision-making in the current era of global competition [6].

In contrast to the traditional costing systems, $A B C$ is more reliable in providing accurate cost estimates for various objects, such as products, services, processes, projects, or customer segments [5]. ABC uses activities as a medium to trace costs rather than arbitrarily allocating them as it is done under the traditional costing systems [1]. After implementation, many companies were able to derive tangible benefits from using $A B C$ by reducing overall costs, establishing new pricing policies, identifying opportunities for improvement, and determining a more profitable product mix [2]. Frequently, the $A B C$ analysis established the foundation for Activity-Based Management (ABM), defined as a set of actions based on $A B C$ analysis and conducted to increase efficiency, lower costs, and to improve asset utilization [4].

Although the $A B C / A B M$ methodology appears to be an excellent managerial tool for Internet companies, this subject has not been featured prominently in the work of academic researchers. As it is the case with the small manufacturing companies, where ABC implementations differ from large manufactures [11], it could be reasonably expected that $A B C / A B M$ for e-commerce will be also different. Thus, this paper examines the application of ABC/ABM specifically to e-commerce. In essence, this paper builds on our earlier work [12] that proposed to use $A B C$ for e-commerce. In contrast, however, the major objective and contribution of this paper is to expand the investigation to $A B M$ methodology [12]. By providing a step-by-step ABC/ABM implementation procedure, this paper also aims to help managers in companies engaged in e-commerce to gain an understanding of the value of a dependable costing system.

The remainder of the paper is constructed as follows. The next section describes the proposed $A B C / A B M$ implementation procedure for e-commerce. This procedure is then illustrated with an application example from a fictitious Internet company. In the next section, the ABC analysis serves for discussion about ABM. Finally, the paper concludes with pointing to the advantages of ABM for e-commerce.

\section{Methodology}

The $A B C / A B M$ implementation methodology discussed in this paper was originally developed for small manufacturing companies [13] with the objective of effective implementation. The described methodology, adapted to specific needs of e-businesses [12] makes use of matrixes (or tables) to trace overhead. The implementation procedure is performed in seven major steps, as outlined in the following section.

\subsection{Step 1: Establish Objective and Requirements of the Costing System}

At the beginning of the ABC/ABM implementation, the company's management must decide about the major purpose for using the costing system. For example, common objectives of a costing system are controlling costs and measuring profitability. No matter what the primary objectives, the underlying goal of ABC is to target overhead costs. Examples of overhead include rent, administrative salaries, office expenses, and utility costs. Depending upon the objectives, management must also choose upon the level of accuracy for their costing system. A highly accurate costing system may require a more advanced computer and network infrastructure necessary for the collection of the necessary data, which will result in higher cost.

During step 1, based on the objective for using the costing system, management must decide about which cost objects will be used in the analysis. For example, a company interested in assessing the profitability of their customers may choose customer segments as cost objects while a company mostly interested in controlling costs 
associated with distribution of products may decide to use products or product lines as cost objects. The objective and requirements of the $A B C$ system should be consistent with the overall business strategy of a given company.
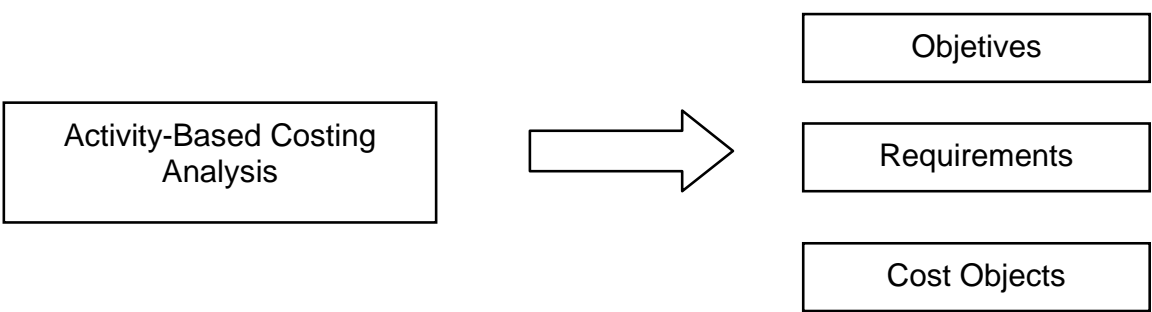

Figure 1: Acitivity-Based Costing Analysis

\subsection{Step 2: Identify Business Activities}

Subsequently, the activities (which cause overhead-related expenses) must be identified and described preferably by "active" phrases [9]. Value chain analysis could be used for this purpose [15]. A typical value chain for an Internet company may start with activities needed to build demand for company's products such as marketing products and maintaining Web sites. Then other activities in the value chain, such as processing customer orders, handling inventory, and shipping products may follow. All of these activities are direct value-adding activities and are linked directly to the distribution of products, the completion of jobs, or other activities serving customers. In addition, a company may also posses a number of activities, which are defined as supporting activities, such as performing human resource duties. This initial categorization of activities may help the management to prioritize their attention when performing ABM later on.

\subsection{Step 3: Trace Overhead to Activities by Using the Expense-Activity-Dependence (EAD) Matrix}

After major activities are identified, overhead is traced from expenses to activities. During this step, the overhead expenses are obtained from accounting records and then related to activities by using the Expense-ActivityDependence (EAD) matrix [13]. In essence, the EAD matrix helps to determine the overhead consumption by each activity.

\subsection{Step 4: Trace Overhead to Cost Objects by Using the Activity-Product-Dependence (APD) Matrix}

Once the costs for peforming all activities are determined, the Activity-Product-Dependence (APD) matrix is used to relate activities to cost objects [13]. The APD matrix is also used to trace the overhead consumption of particular cost objects.

\subsection{Step 5: Trace Direct Cost to Cost Objects}

In addtion to overhead expenses, there are costs that could be directly assigned to cost objects. Thus, during this step all direct costs are indentified and assigned to cost objects.

\subsection{Step 6: Calculate Product Cost of Each Cost Object}

Product cost, or an estimate of the total costs occurring when generating a cost object, is calculated by adding the direct cost and overhead together.

\subsection{Step 7: Use of the ABC Analysis for Operational and Strategic Decision-Making}

Once the $A B C$ analysis is performed (Steps 2-6), the information gained can be used to perform ABM. As part of $A B M$, managers would need to properly interpret the results of the $A B C$ analysis and then take actions with the objective of improving operational and strategic performance.

The seven step ABC/ABM implementation procedure is depicted in Figure 1 
Step 1

Establish Objectives and Requirements of the Costing System

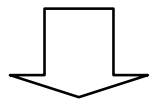

Step 2

Identify Business Activities

Step 3<smiles>C1C[C]2CC[C]1C2</smiles>

\section{Step 4}

Trace Overhead to Cost Objects

Step 5
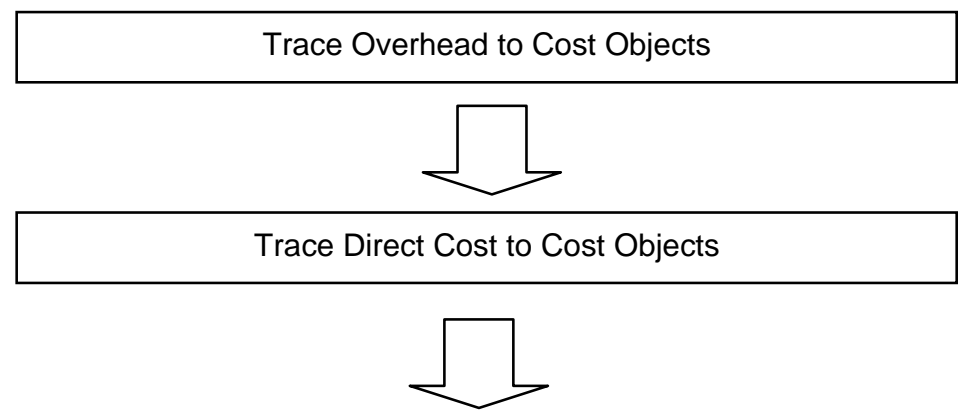

Step 6

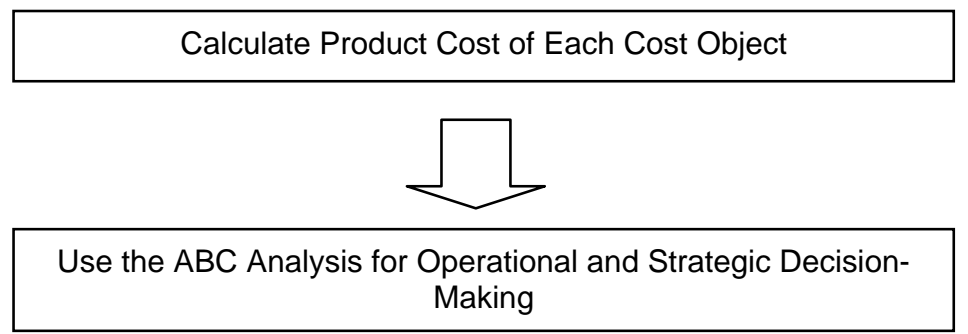

Step 7

Figure 2: Implementation Procedure

\section{Applications Example}

HighQualityTools.com (HQT, a fictitious company, but an appropriate financial and organizational representation of many dot-com's) is a "typical" pure click firm. This Business-to-Customer (B2C) firm sells tools and work-related apparel, mainly to do-it-yourselfers, craftsmen, and industrial workers. In order to build robust customer base, HQT that started its operations a few years ago with practically no customers, performed aggressive marketing campaigns. Incentives for the first-time buyers, such as substantial price reductions and free shipping are also offered. Although most of the initial sales were unprofitable, HQT hopes that most of the first-time buyers will become loyal customers and will eventually contribute to their profits.

The ABC analysis for HQT has two main objectives. The first is to verify the profitability of loyal customers. The second objective of the $A B C$ analysis is to identify profitable and unprofitable product lines. Thus, for the first objective the cost objects are customers' groups according to the length of their patronization and for the second objective the product lines.

Independently from the objetives of the $A B C$ system, the $A B C$ analysis started with examining financial reports for overhead expenses as sumarized in Table 1.

The "General and Administrative" expenses category includes mainly executive and administrative salaries. The "Technology" expense category includes mainly software and hardware acquisition costs; while "Depreciation" reflects the reduction in the value of hardware and office equipment. Most of these expenses are also expected in a traditional "brick-and-mortar" company. Characteristics of HQT, however, are its relatively high sales and marketing costs. Expenses related to hardware and software are high, which is also a characteristic that can be seen in most e- 
businesses. In order to ensure that HQT's overhead expense categories are representative to a "typical" B2C company, financial statements of publicly traded companies were studied.

Table 1: Overhead expense categories

\begin{tabular}{|l|r|}
\hline \multicolumn{1}{|c|}{ Expense Category } & \multicolumn{1}{c|}{ Cost } \\
\hline General and Administrative & $\$ 200,000.00$ \\
\hline Rent and Utilities & $\$ 80,000.00$ \\
\hline Office Expenses & $\$ 30,000.00$ \\
\hline Technology & $\$ 150,000.00$ \\
\hline Depreciation & $\$ 40,000.00$ \\
\hline Sales and Marketing & $\$ 180,000.00$ \\
\hline Miscellaneous & $\$ 20,000.00$ \\
\hline Total & $\$ \mathbf{7 0 0 , 0 0 0 . 0 0}$ \\
\hline
\end{tabular}

Since the first objective of the $A B C$ analysis was to determine the profitability of customers' groups according to the length of their patronization, all customers are categorized based on the length of their business with HQT. Customers who only placed an initial order (with no subsequent orders in the given time period) are assigned into the category "New," while returning customers are grouped according to the length of their patronization as "Short," "Mid," or "Long-term." Table 2 depicts the information pertaining to the customers' groups, as cost objects.

Table 2: Customer classification according to the length of patronization

\begin{tabular}{|l|l|}
\hline Customers & Length of Patronization \\
\hline New & Initial Order \\
\hline Short-term & Less than 1 year \\
\hline Mid-term & 1 year to 2 years \\
\hline Long-term & More than 2 years \\
\hline
\end{tabular}

In step 2, all tasks consuming overhead resources are grouped into business activities. In this illustration, the relatively low number of activities is intended to focus the reader's attention more on methodology than on accounting details. In general, a low number of activities is an indication of a modest level of accuracy of the costing system. A higher level of accuracy would require a usage of a higher number of activities. Typically, the average number of activities would range between twenty and sixty for a costing system that is mainly strategic, while a primarily operational costing system would require several hundred activities [4]. Table 3 depicts the ten main business activities for HQT.

Table 3: Major business activities of HighQualityTools.com

\begin{tabular}{|l|}
\hline \multicolumn{1}{|c|}{ Activity } \\
\hline Market Products \\
\hline Maintain Web Pages \\
\hline Maintain Customer Database \\
\hline Maintain Payment System \\
\hline Manage Customer Orders \\
\hline Manage Customer Inquiries \\
\hline Acquire Goods \\
\hline Receive and Handle Goods \\
\hline Monitor Quality \\
\hline Prepare Goods for Shipment \\
\hline
\end{tabular}

As mentioned earlier, most of the activities depicted in Table 3 could also be found in a traditional "brick-and-mortar" company. A distinguishing characteristic of an Internet company, however, lies in the importance (and, therefore cost) of particular activities. For example, for an Internet company the activity "Maintain Web Pages" is extremely crucial, as it provides the only link to customers. In contrast, for a traditional "brick-and-mortar" business maintaining the company website would be a supporting activity as the website is solely used for information [10].

In step 3, the cost of each activity is estimated by using the Expense-Activity-Dependence (EAD) matrix [13]. In the EAD matrix, the columns represent the overhead expense categories and the rows represent the activities. If the given activity consumes a given expense, the percentage of its overall expense (ranging from 0 to 100 and represented by a number between 0 and 1 ) is placed on the intersection. This number represents the proportion of the expense category caused by a particular activity. This consumption rate could be gleaned from reviewing financial records, or, in the event that the accounting data is not available, by educated guessing or estimation. For 
example, in the illustration, the activity "Market Products" is responsible for $\$ 20,000.00$, or ten percent of the expense category "General and Administrative" costs, which is $\$ 200,000.00$. Therefore, the figure of 0.1 is placed on the intersection of the expense category "General and Administrative" and the activity "Market Products."

After all numbers are placed in the matrix, the cost of each activity is calculated by multiplying the percentage by the total expenses. For example, the total cost for the activity "Monitor Quality" would be $\$ 45,000.00(0.1 \times 200+0.1 \times$ $80+0.1 \times 150+0.1 \times 20)$. The total activity cost for all activities should be equal to the total expenses for all expense categories. For the purpose of simplification, it is assumed that available capacity and used capacity are equal. Thus, the cost of used capacity is not taken into account. In reality, many Internet companies pose excess capacity and this simplification may lead to systematic overpricing of products and services [3]. Table 4 presents the EAD matrix for HQT. (For a more detailed description of the procedure, refer to work by Roztocki et al. [13])

Table 4: Expense-Activity-Dependence (EAD) matrix (in thousands)

\begin{tabular}{|c|c|c|c|c|c|c|c|c|}
\hline \multirow[b]{2}{*}{ Activity } & \multicolumn{7}{|c|}{ Expense Category } & \multirow[b]{2}{*}{$\begin{array}{l}\text { Total } \\
\text { Activity } \\
\text { Cost }\end{array}$} \\
\hline & 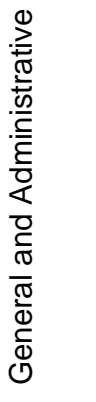 & 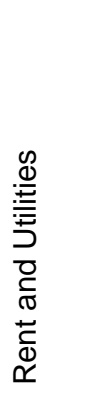 & 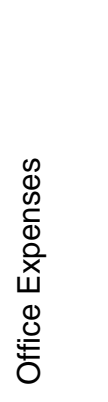 & $\begin{array}{l}\text { ठे } \\
\frac{0}{0} \\
\frac{0}{0} \\
\text { ट } \\
\stackrel{0}{-}\end{array}$ & 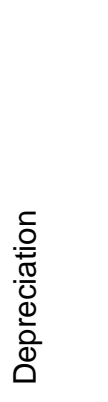 & 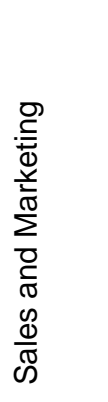 & $\begin{array}{l}\mathscr{N} \\
\overline{0} \\
\Phi \\
\frac{D}{\sigma} \\
\overline{\bar{D}} \\
\stackrel{0}{\Sigma}\end{array}$ & \\
\hline Market Products & 0.1 & 0.1 & 0.4 & 0.1 & & 0.4 & 0.1 & 129 \\
\hline Maintain Web Pages & 0.1 & 0.1 & 0.1 & 0.1 & 0.2 & 0.1 & 0.1 & 74 \\
\hline Maintain Customer Database & & & & 0.1 & 0.2 & & 0.1 & 25 \\
\hline Manage Payment System & & & & 0.1 & 0.1 & & 0.1 & 21 \\
\hline Manage Customer Orders & 0.2 & 0.1 & 0.1 & 0.1 & 0.1 & 0.2 & 0.1 & 110 \\
\hline Manage Customer Inquiries & 0.1 & 0.1 & 0.1 & 0.1 & 0.1 & 0.2 & 0.1 & 88 \\
\hline Acquire Goods & 0.2 & 0.1 & 0.2 & 0.1 & 0.1 & 0.1 & 0.1 & 95 \\
\hline Receive and Handle Goods & 0.1 & 0.2 & 0.1 & 0.1 & 0.1 & & 0.1 & 60 \\
\hline Monitor Quality & 0.1 & 0.1 & & 0.1 & & & 0.1 & 45 \\
\hline Prepare Goods for Shipment & 0.1 & 0.2 & & 0.1 & 0.1 & & 0.1 & 57 \\
\hline Total Expenses & 200 & 80 & 30 & 150 & 40 & 180 & 20 & 700 \\
\hline
\end{tabular}

In step 4, the Activity-Product-Dependence (APD) matrix is applied to assign the overhead from activities to cost objects [13]. In the APD matrix, the columns represent the activities, while the rows represent the cost objects. If the given cost object triggers the need to carry out the particular activity, a number between 0 and 1 (representing the percentage) is placed on the intersection. As in the EAD matrix, this number can be derrived from reviewing financial records or by estimation. After all numbers are placed, the overhead consumption for each cost object is calculated by multiplying the percentage by the total expenses. Table 5 shows the APD matrix for HQT.

In step 5, the direct costs for each customer group is determined. Frequently, the largest portion of direct costs are the expenses associated with acquiring various products from HQT suppliers.

In step 6, the cost of servicing each customer group is calculated by adding the previously traced overhead costs for each customer group to the direct cost, as depicted in Table 6. Often, because of less need for retention efforts, the overhead cost for servicing long-term customers may be lower. 
Table 5: Activity-Product-Dependence (APD) matrix (in thousands)

\begin{tabular}{|c|c|c|c|c|c|c|c|c|c|c|c|}
\hline \multirow[b]{2}{*}{$\begin{array}{l}\text { Cost Object } \\
\text { (Customers } \\
\text { grouped according } \\
\text { to length of } \\
\text { patronization) }\end{array}$} & \multicolumn{10}{|c|}{ Activity } & \multirow[b]{2}{*}{$\begin{array}{l}\text { Total } \\
\text { Overhead } \\
\text { Cost } \\
\text { of each } \\
\text { Object } \\
\text { Cost }\end{array}$} \\
\hline & 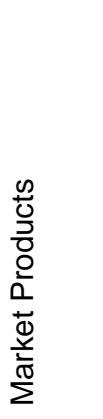 & 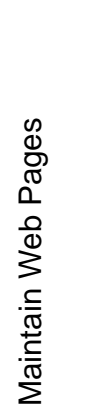 & 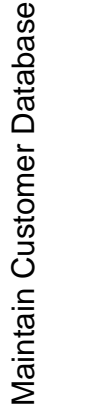 & 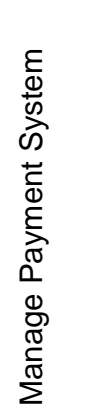 & 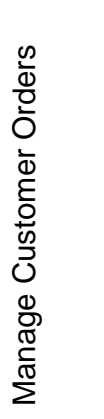 & 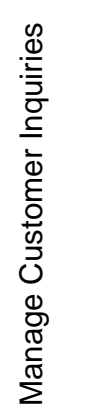 & $\begin{array}{l}0 \\
0 \\
0 \\
0 \\
0 \\
.0 \\
\overline{0} \\
\frac{0}{4}\end{array}$ & 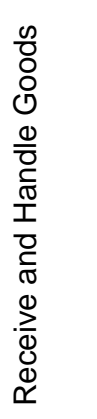 & 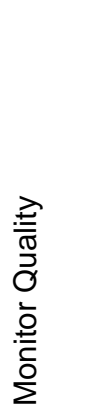 & 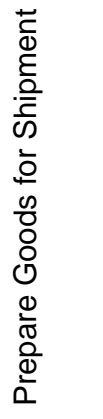 & \\
\hline New & 0.7 & 0.4 & 0.4 & 0.4 & 0.4 & 0.7 & 0.25 & 0.25 & 0.25 & 0.25 & 307 \\
\hline Short-term & 0.1 & 0.2 & 0.2 & 0.2 & 0.2 & 0.1 & 0.25 & 0.25 & 0.25 & 0.25 & 131 \\
\hline Mid-term & 0.1 & 0.2 & 0.2 & 0.2 & 0.2 & 0.1 & 0.25 & 0.25 & 0.25 & 0.25 & 131 \\
\hline Long-term & 0.1 & 0.2 & 0.2 & 0.2 & 0.2 & 0.1 & 0.25 & 0.25 & 0.25 & 0.25 & 131 \\
\hline Total Expenses & 129 & 74 & 25 & 21 & 110 & 88 & 95 & 60 & 45 & 57 & 700 \\
\hline
\end{tabular}

Table 6: Estimated product cost for each customer group

\begin{tabular}{|l|r|r|r|}
\hline \multicolumn{1}{|c|}{ Cost Object } & \multicolumn{1}{c|}{ Direct Cost } & \multicolumn{1}{c|}{ Overhead Cost } & \multicolumn{1}{c|}{ Product Cost } \\
\hline New & $\$ 187,000.00$ & $\$ 307,000.00$ & $\$ 494,000.00$ \\
\hline Short-term & $\$ 166,000.00$ & $\$ 131,000.00$ & $\$ 297,000.00$ \\
\hline Mid-term & $\$ 165,000.00$ & $\$ 131,000.00$ & $\$ 296,000.00$ \\
\hline Long-term & $\$ 182,000.00$ & $\$ 131,000.00$ & $\$ 313,000.00$ \\
\hline Total & $\mathbf{\$ 7 0 0 , 0 0 0 . 0 0}$ & $\mathbf{\$ 7 0 0 , 0 0 0 . 0 0}$ & $\mathbf{\$ 1 , 4 0 0 , 0 0 0} .00$ \\
\hline
\end{tabular}

The operating profit (or operating loss) generated from each customer group is calculated by subtracting product costs from revenues as summarized in Table 7.

Table 7: Profitability analysis for each customer group

\begin{tabular}{|l|r|r|r|}
\hline \multicolumn{1}{|c|}{ Cost Object } & Revenues & \multicolumn{1}{c|}{ Product Cost } & \multicolumn{1}{c|}{ Operating Profit } \\
\hline New & $\$ 290,000.00$ & $\$ 494,000.00$ & $-\$ 204,000.00$ \\
\hline Short-term & $\$ 300,000.00$ & $\$ 297,000.00$ & $\$ 3,000.00$ \\
\hline Mid-term & $\$ 260,000.00$ & $\$ 296,000.00$ & $-\$ 36,000.00$ \\
\hline Long-term & $\$ 250,000.00$ & $\$ 313,000.00$ & $-\$ 63,000.00$ \\
\hline Total & $\$ 1,100,000.00$ & $\$ 1,400,000.00$ & $\$-300,000.00$ \\
\hline
\end{tabular}

In the illustration, the category of newly acquired customers shows a high amount of loss. The operating profit for "Short-term" customers is marginally positive, while the more established "Mid-term" and "Long-term" customers once again show losses. The profit from "Short-term" customers, as the managers later discovered, was oftentimes an illusion caused by delays between the purchase and the return of items and the accumulated costs associated with the correction of processing and shipping errors. Initial recorded profit often turned out to be a subsequent recorded loss. Frequently, the loss was recorded after some time period as the particular customer was categorized no longer as "Short-term" but as "Mid-term." The losses from "Mid-term" and "Long-term" customers are also attributed to a high return rate and order processing errors, but there is no illusionary profitability because the duration over which these transactions were monitored was long enough to take returns (losses) into account.

In contrast to $\mathrm{ABC}$ analysis, a traditional volume-based approach would allocate overhead instead of tracing it. Overhead, which comprises $\$ 700,000.00$ (or fifty percent) of HQT's overall expenses, could then be allocated based on direct costs. In other words, according to the traditional approach on each one dollar of direct cost, one dollar of overhead would be allocated. Based on this kind of allocation, the product cost for "New" customers would be $\$ 374,000.00$ ( $\$ 187,000.00+\$ 187,000.00)$ instead of $\$ 494,000.00$ as shown by the ABC analysis. The traditional approach would, therefore, tend to underestimate the total cost related to customer acquisition.

As previously mentioned, the second objective of the $A B C$ analysis is to determine profitable and unprofitable product lines. In this part of the analysis, instead of customer groups, the cost objects are HQT's major product lines. Thus, in this part of the analysis, all items offered online are divided into four categories: "Hand Tools," "Power 
Tools," "Landscaping Tools," and "Work-Related Apparel." Additionally, a fifth category of "Miscellaneous" contains mainly small items such as flashlights, batteries, electrical cords, and electrical testers. The product lines, as cost objects, are presented in Table 8.

Table 8: Product lines

\begin{tabular}{|l|}
\hline Product Line \\
\hline Hand Tools \\
\hline Power Tools \\
\hline Landscaping Tools \\
\hline Work-Related Apparel \\
\hline Miscellaneous \\
\hline
\end{tabular}

Since the $A B C$ analysis for product lines was conducted in the same manner as it was for analyzing customer profitability, the following tables summarize only the final results of the analysis, skipping all the intermediate steps. Table 9 depicts the estimated product cost for each product line, while Table 10 presents profitability analysis.

Table 9: Estimated product cost for each product line

\begin{tabular}{|l|r|r|r|}
\hline \multicolumn{1}{|c|}{ Cost Object } & \multicolumn{1}{c|}{ Direct Cost } & \multicolumn{1}{c|}{ Overhead Cost } & \multicolumn{1}{c|}{ Product Cost } \\
\hline Hand Tools & $\$ 130,000.00$ & $\$ 110,000.00$ & $\$ 240,000.00$ \\
\hline Power Tools & $\$ 290,000.00$ & $\$ 300,000.00$ & $\$ 590,000.00$ \\
\hline Landscaping Tools & $\$ 120,000.00$ & $\$ 120,000.00$ & $\$ 240,000.00$ \\
\hline Work-Related Apparel & $\$ 80,000.00$ & $\$ 80,000.00$ & $\$ 160,000.00$ \\
\hline Miscellaneous & $\$ 80,000.00$ & $\$ 90,000.00$ & $\$ 170,000.00$ \\
\hline Total & $\mathbf{\$ 7 0 0 , 0 0 0 . 0 0}$ & $\mathbf{\$ 7 0 0 , 0 0 0 . 0 0}$ & $\mathbf{\$ 1 , 4 0 0 , 0 0 0 . 0 0}$ \\
\hline
\end{tabular}

Table 10: Profitability analysis for each product line

\begin{tabular}{|l|r|r|r|}
\hline \multicolumn{1}{|c|}{ Cost Object } & \multicolumn{1}{c|}{ Revenues } & \multicolumn{1}{c|}{ Product Cost } & \multicolumn{1}{c|}{ Operating Profit } \\
\hline Hand Tools & $\$ 230,000.00$ & $\$ 240,000.00$ & $-\$ 10,000.00$ \\
\hline Power Tools & $\$ 400,000.00$ & $\$ 590,000.00$ & $-\$ 190,000.00$ \\
\hline Landscaping Tools & $\$ 180,000.00$ & $\$ 240,000.00$ & $-\$ 60,000.00$ \\
\hline Work-Related Apparel & $\$ 170,000.00$ & $\$ 160,000.00$ & $\$ 10,000.00$ \\
\hline Miscellaneous & $\$ 120,000.00$ & $\$ 170,000.00$ & $-\$ 50,000.00$ \\
\hline Total & $\mathbf{\$ 1 , 1 0 0 , 0 0 0 . 0 0}$ & $\mathbf{\$ 1 , 4 0 0 , 0 0 0 . 0 0}$ & $\mathbf{- \$ 3 0 0 , 0 0 0 . 0 0}$ \\
\hline
\end{tabular}

In this illustration, the $A B C$ analysis indicates that most of the product lines unprofitable. For example, the "Miscellaneous" product line, which contains primarily small and relatively inexpensive items, is showing a negative operating profit of $\$ 50,000.00$. The reason for this is the fact that the sales cannot compensate for the amount it costs to inventory, stock, pack and list the small items. Moreover, the "Power Tools" product line is even less profitable than the "Miscellaneous" product line. This product line contains mainly large and expensive items, such as generators, table saws, air compressors, and pressure washers. Thus, the "Power Tools" product line's lack of profitability is a direct result of comparison-shopping. Frequently, HQT was forced to reduce the price in response to special offers made by their competitors. Moreover, high storage and shipment costs were cited as a secondary reason for the lack of profitability of this product line. HQT's management also believed that because they sold less of these items than their larger competitors, they were not able to take part in the principles of the "economies of scale", which resulted in unfavorable procurement costs.

In step 7, after recognizing from $A B C$ analysis that a more radical change is needed to reach the profitability, HQT's management was influenced to actively engage in $A B M$ as part of a new corporate strategy.

\section{Activity-Based Management}

In essence, $A B M$ is defined as implementing a number of managerial steps derived from the output of the $A B C$ analysis [4]. These managerial actions can be divided into two major categories: operational and strategic ABM. Operational $A B M$ seeks to improve what is already in existence, while strategic ABM seeks major changes. Thus, operational $A B M$ utilizes the $A B C$ analysis to identify the ways to perform the existing activities more efficiently. In contrast, strategic $A B M$ uses the $A B C$ analysis to shift the demand from activities that consume an excessive level of resources to those that consume only a minimal level while yielding higher output. In other words, the strategic ABM seeks to assign the most valued overhead resources as efficient as possible. 
In the case of $\mathrm{HQT}$, both operational and strategic ABM options are possible. Using the operational ABM approach options for improvement are focusing on order processing and handling of customer complaints. Numerous mistakes in shipping and the subsequent customer complaints (which are often handled slow and incompetently) are causing substantial costs. The solutions using operational ABM include the implementation of a Customer Relationship Management (CRM) system and comprehensive training methods for both storage workers and customer service representatives. This would limit shipment mistakes and help to solve many problems the first time. An incentive system could be combined with this approach to reward diligent and error-free work.

The strategic ABM approach also offers other improvements possibilities. As previously mentioned, the existing strategy of HQT is based on the assumption that the aggressive acquisition of new customers is their first priority. It was hoped that these new customers would eventually make enough purchases to become profitable, enabling the company to generate attractive returns for investors. The $A B C$ analysis reveals that the current passive strategy of waiting until the unprofitable customers became profitable was not very promising. One of the many strategic options to remedy this was to develop a new, more focused, strategy of customer acquisition. Such a strategy could be devised by extracting useful information from existing sales records. For instance, HQT can use data mining and create a general profile of a "desirable" buyer. This profile could then be used in targeting more specific prospective customers.

Furthermore, the $A B C$ analysis reveals that some of the product lines are highly unprofitable. For example, the "Power Tools" product line was responsible for more than half of HQT's overall losses. The initial investigation suggests that this product line is not likely to be profitable in the future because of fierce competition and high storage and handling costs. Discontinuing this unprofitable product line would be another example of strategic ABM due to the drastic nature of the change for HQT's product mix. This strategic approach could be used either to reduce overhead resources or to shift them to new, more profitable product lines.

\section{Conclusions}

The case of HQT indicates that ABC/ABM is not only useful to established "brick-and-mortar" companies but may also be useful to e-businesses as well. In addition, ABC/ABM appears to have the potential to lead e-businesses toward efficient levels of operations and more professional business strategies. The ABC analysis allows managers to reliably measure costs associated with e-commerce, helping them to weigh the costs and benefits and to prioritize their attention. Moreover, it provides them with a better understanding of how these costs are generated and subsequently allows them to actively perform ABM.

In this paper a fictitious B2C company is used to discuss benefits of using ABC/ABM to e-businesses. Future studies may collect empirical evidence and refine the proposed implementation procedure. One possible research project may for example use the actions research methodology and implement ABC in a number of real e-businesses [14].

In summary, it could be reasonably expected that implementation of ABC/ABM will benefit companies engaged in ecommerce, enabling a better operational performance and improve business strategies and, thus, will lead them toward the main goals of a for-profit-organization: profitability.

\section{Acknowledgments}

Earlier version of this paper was presented at the Second Workshop on e-Business (WeB 2003) in Seattle, WA, December 13-14, 2003. The valuable feedback received from the workshop participants is greatly appreciated. Furthermore, this paper greatly benefited from the helpful comments provided by four anonymous reviewers.

\section{References}

[1] R. Cooper, The Rise of Activity-Based Costing - Part One: What is an Activity-Based Cost System?, Journal of Cost Management, vol. 2, no. 2, pp. 45-54, 1988.

[2] R. Cooper and R.S. Kaplan, Profit Priorities from Activity-Based Costing, Harvard Business Review, vol. 69, no. 3, pp. 130-135, 1991.

[3] R. Cooper and R.S. Kaplan, Activity-Based Systems: Measuring the Costs of Resource Usage, Accounting Horizons, vol. 6, no. 3, pp. 1-12, 1992.

[4] R. Cooper and R.S. Kaplan, The Design of Cost Management System, Second Edition ed. Upper Saddle River, New Jersey: Prentice Hall, 1999.

[5] A. Gunasekaran, H.J. Williams, and R.E. McGaughey, Performance Measurement and Costing System in New Enterprise, Technovation, vol. 25, no. 5, pp. 523-533, 2005.

[6] K.M. Gupta and A. Gunasekaran, Costing in New Enterprise Environment: A Challenge for Managerial Accounting Researchers and Practitioners, Managerial Auditing Journal, vol. 20, no. 4, pp. 337-353, 2005.

[7] J. Hayes and P. Finnegan, Assessing the Potential of e-Business Models: Towards a Framework for Assisting Decision-Makers, European Journal of Operational Research, vol. 160, no. 2, pp. 365-379, 2005. 
[8] H.T. Johnson, Activity Management: Reviewing the Past and Future of Cost Management, Journal of Cost Management, vol. 3, no. 4, pp. 4-7, 1990.

[9] H.T. Johnson, Activity-Based Management: Past, Present, and Future, The Engineering Economist, vol. 36, no. 3, pp. 219-38, 1991.

[10] M. Ko and N. Roztocki, Investigating the Impact of Firm Strategy - Click-and Brick, Brick-and-Mortar, and PureClick - on Financial Performance, Journal of Information Technology Theory and Application, vol. 10, no. 2, pp. 4-18, 2009.

[11] K.L. Needy, H. Nachtmann, N. Roztocki, R.C. Warner, and B. Bidanda, Implementing Activity-Based Costing Systems in Small Manufacturing Firms: A Field Study, Engineering Management Journal, vol. 15, no. 1, pp. 3-10, 2003.

[12] N. Roztocki, "Activity-Based Costing for E-Commerce," in Industrial Engineering research '2001 Conference, Institute of Industrial Engineers, 2001.

[13] N. Roztocki, J.D. Porter, R.M. Thomas, and K.L. Needy, A Procedure for Smooth Implementation of ActivityBased Costing in Small Companies, Engineering Management Journal, vol. 16, no. 4, pp. 19-27, 2004.

[14] N. Roztocki and H.R. Weistroffer, Evaluating Information Technology Investments: A Fuzzy Activity-Based Costing Approach, Journal of Information Science and Technology, vol. 2, no. 4, pp. 30-43, 2005.

[15] N. Roztocki and H.R. Weistroffer, Evaluating Investments For Services: A Value Chain Analysis Framework, Journal of Service Science, vol. 1, no. 2, pp. 47-56, 2008.

[16] J. Thornton and S. Marche, Sorting Through the dot Bomb Rubble: How Did the High-Profile e-Tailers Fail?, International Journal of Information Management, vol. 23, no. 2, pp. 121-138, 2003.

[17] P.R. Wheale and L.H. Amin, Bursting the dot-com 'Bubble': A Case Study in Investor Behaviour, Technology Analysis \& Strategic Management, vol. 15, no. 1, pp. 117-136, 2003. 